\title{
Advantages of the Use of Deciduous Teeth, Hair, and Blood Analysis for Lead and Cadmium Bio-Monitoring in Children. A Study of 6-Year-Old Children from Krakow (Poland)
}

\author{
Henryk J. Barton
}

Received: 4 October 2010 / Accepted: 1 November 2010 /

Published online: 18 November 2010

(C) The Author(s) 2010. This article is published with open access at Springerlink.com

\begin{abstract}
The population of about 300 6-year-old preschool children was studied for lead $(\mathrm{Pb})$ and cadmium $(\mathrm{Cd})$ in deciduous teeth, scalp hair, and capillary blood. Zinc ( $\mathrm{Zn})$ content in hair was also measured due to its possible interferences with the elements studied. The $\mathrm{Pb}$ and $\mathrm{Cd}$ contents were measured by graphite furnace atomic absorption spectrometry with Zeeman background correction, and Zn, by flame method. Metal levels found were comparable to those in European countries. Positive correlations between $\mathrm{Pb}$ and $\mathrm{Cd}$ in the same and different tissues were widespread $(r=0.23-0.68)$. A positive correlation was found between $\mathrm{Pb}$ in teeth and blood $(r=0.65, p<0.001)$. $\mathrm{Pb}$ blood threshold $100 \mu \mathrm{g} \mathrm{L}^{-1}$ referred to $2.6 \mu \mathrm{g} \mathrm{g}^{-1} \mathrm{~Pb}$ in teeth. Predictability of this $\mathrm{Pb}$ teeth limit was $14 \%$ vs. $5 \%$ for $\mathrm{Pb}$ blood. Strong negative correlation was found between hair $\mathrm{Pb}$ and $\mathrm{Zn}(r=-0.68, p<0.001)$. Enhanced $\mathrm{Cd}$ and $\mathrm{Zn}$ levels in hair were associated with the household drinking water hardness. The associations with some other environmental and behavioral factors were also presented and discussed. The results proved the advantage of analysis of primary teeth for $\mathrm{Pb}$ exposure screening of preschool children.
\end{abstract}

Keywords Environmental exposure $\cdot$ Children $\cdot$ Bio-monitoring $\cdot$ Primary teeth $\cdot$ Hair $\cdot$ Blood $\cdot$ Lead $\cdot$ Cadmium $\cdot$ Zinc

\section{Introduction}

Cadmium $(\mathrm{Cd})$ and lead $(\mathrm{Pb})$ have been extensively emitted to the human environment because of human activities including burning of fossil fuels, mining, industrial processes,

Preliminary work by Barton H, Folta M, and Zachwieja Z entitled "The application of deciduous teeth as a biomarker of long-term environmental $\mathrm{Pb}$ exposure of children. The study in Kraków in 2001" was presented at the Conference in "Molecular Epidemiology in Preventive Medicine. Achievements and New Challenges", Krakow, Poland 20-22.06.2002.

H. J. Barton $(\bowtie)$

Department of Food Chemistry and Nutrition, Medical College, Jagiellonian University, Medyczna 9, PL-30-688 Cracow, Poland e-mail: mfbarton@cyf-kr.edu.pl 
and leaded gasoline use. For lead in the environment, preventive actions were undertaken relatively early, while for cadmium, due to a wide usage of its components in current technology, its deposition in the environment continues, e.g., [1].

Since a majority of lead emissions during the last decades had been derived from exhaust gases of vehicles, the impact of leaded gasoline replacement is clearly observed $[2,3]$. This resulted in a significant reduction of high-level domains of environmental lead; however, former lead deposits still remain, e.g., [4, 5].

Cadmium is present in soil as natural constituents and introduced as contaminant from fertilizers [6]. It has been introduced also to the environment at high levels by some industrial branches, like zinc ores mining and associated industry. Reductions of common $\mathrm{Pb}$ and $\mathrm{Cd}$ industrial emission sources, like, from heavy industries, have curtailed the high-pollution areas and lowered general exposure of population evident in some European countries [7, 8]. The low-level sources of pollutions are still widespread, and it can be difficult to reduce it.

Chronic low-level toxicity of lead and cadmium came into view in recent years as a problem of our civilization. General health effects to be considered associated with exposure to these metals comprise systemic, immunological, neurological, reproductive [9], developmental, genotoxic and carcinogenic, [10] and even death [11]. The metals can induce DNA damage $[12,13]$ as well as disturb its repair [14].

Cadmium accumulates mainly in the kidney and is nephrotoxic. However, increased Cd was also observed in male reproductive organs. Direct effect on induction of osteoporosis has not been proved [1]. Intoxication may persist especially longer for cadmium, which, if had been accumulated in childhood, can affect the health for decades of the developing organism [15]. The recent studies on cadmium reviewed by ATSDR (2008) [11] have shown that even low cadmium burdens may produce subtle effects on the proximal tubule in children [16]. The studies indicated consistently that renal tubular damage $[17,18]$ due to exposure to cadmium develops at lower levels of cadmium body burden than previously anticipated. The comprehensive analysis of health effects of $\mathrm{Cd}$ performed by Järup et al. (2009) [17] implies that, "no margin of safety exists between the point of departure and the exposure levels in the general population". Therefore, they concluded that "measures should be put in place to reduce exposure to a minimum". Such efforts are recently undertaken with the aim to establish reliable Cd exposure markers and limitations [19].

In a developing nervous system, the hematological and cardiovascular systems, and the kidney are the most sensitive targets for lead toxicity [20]. However, due to the multi-modal action of lead in biological systems, it could potentially affect any system or organ in the body. Especially in children, $\mathrm{Pb}$ can disturb several neurophysiological functions, those that can affect their development and further the whole life. Because lead poisoning often occurs with no obvious symptoms, it frequently remains unrecognized. However, Winneke et al. [21], by the use of advanced methods in the study, found a subtle neurobehavioral dysfunction in 6-year-children, and it was suggested to be associated with very low $\mathrm{Pb}$ in blood.

At a low and moderate pollution of the environment, diet can be the primary route of exposure to $\mathrm{Pb}$ and $\mathrm{Cd}$ for the general population [11,20]; however, the external sources of exposure can locally [22] and periodically [23] change the proportions. Recent studies in a variety of countries have indicated strong environmental variations of balance between gasoline lead, diffuse industrial lead, and possibly local sources [4, 24]. The $\mathrm{Pb}$ isotope ratio study in the area of Krakow and southern Poland has suggested that $\mathrm{Pb}$ in the hair of children, to a major extent, has isotopic characteristics of the airborne particulate matter (PM10, PM2.5), rather than leaded gasoline, not yet restricted in the period of the study [25]. The study in France [26] and review of available $\mathrm{Pb}$ isotopic ratio data for Europe revealed that ultra-low-sized $\mathrm{Pb}$-bearing particles move via over-continental air transfer 
modifying local environmental $\mathrm{Pb}$ composition. This suggests that after decrease of high local $\mathrm{Pb}$ sources of environmental $\mathrm{Pb}$, and possibly $\mathrm{Cd}$, their deposits and circulation will become global.

Several biological materials were investigated to establish children's exposure to lead, including blood, plasma, urine, hair, primary and permanent teeth, nails from fingers and toes, saliva, etc. Hair analysis was conclusively summarized at state on 2001 by the Agency for Toxic Substances and Disease Registry [27]. A comprehensive overview of analytical methods and the usefulness of different biological materials for environmental $\mathrm{Pb}$ exposure bio-monitoring has been recently published [28].

New concerns have been raised as regards $\mathrm{Pb}$ in children, considering possible adverse health effects in children at blood Pb below threshold level $10 \mu \mathrm{g} \mathrm{dL}^{-1}$. Recently established Centers for Disease Control and Prevention (CDC) working group Advisory Committee on Childhood Lead Poisoning Prevention concluded that several studies in the literature had demonstrated a statistically significant association between blood $\mathrm{Pb}$ levels $<100 \mu \mathrm{g} \mathrm{L}^{-1}$ and some adverse health effects in children; however, mild effects observed could conceivably have been influenced by residual confounding factors [29]. The recent study by Hubbs-Tait et al. (2009) found significantly lower perceptual scores (McCarthy Scales of Children's Abilities) in children with lead $>2.5 \mu \mathrm{g} / \mathrm{dL}$ than below this limit. Thus, the suggestion of Canfield et al. (2003) [30] that "perhaps there is no safe threshold for lead but, rather, a continuum of toxic effects" is worth serious concern.

The sampling study in the U.S. (1999-2002) estimated that $1.6 \%$ of children aged 1-5 years had $\mathrm{Pb}$ in blood $\geq 100 \mu \mathrm{g} \mathrm{L}{ }^{-1}$. At present, the U.S. CDC action level for children $\leq 7$ years of age was left at $100 \mu \mathrm{g} \mathrm{L}^{-1}$, while German reference value was stepwisely lowered to $35 \mu \mathrm{g} \mathrm{L}^{-1}[7,8,31,32]$.

In the light of the above findings, the investigations of children's exposure to these metals and monitoring time trends are of key importance. As a part of a series of our reports [33], this article describes the levels and correlations between lead and cadmium in capillary blood, primary teeth, and hair of 6-year-old children from Krakow and southern Poland.

\section{Materials and Methods}

The study area and population were described previously [34]. Briefly, the study population consisted of children living in households investigated in the period 1997-2004 for metal contents in drinking water in Krakow urban (U) and industrial suburban (P) sites, and in rural (R) areas of southeastern Poland. The study group comprised a population of about 300 5-7-year-old preschool children. Children were included in the study upon a written consent signed by their parents. The parents were informed about the aim and procedure of the study and were given respective questionnaire to collect necessary data about their child's health status. After the study, the analytical results of the children were available to the parents on a written form with comments and advices, if needed. The study has been approved by the local Bioethical Commission of the Jagiellonian University. The anthropometrical data of the total group of children were published before [34], and the characteristics of the children participating in the biological part of the study are given in Table 1.

The capillary blood, primary teeth, and hair samples from children were taken in the preschools. The whole procedure was done using the same protocol by the same trained person. The capillary blood was taken according to the procedure based on the CDC protocol [35]. Finger stick capillary blood specimens were collected from the fourth finger of the left hand using an automatic disposable device (lancet penetration depth, $0.9 \mathrm{~mm}$ ). 
Table 1 Anthropometrical data for total study group of children who participated in the biological part of the study $^{\mathrm{a}}$

\begin{tabular}{lclccc}
\hline Group/parameter & Mean & SD & Q25 & MED & Q75 \\
\hline$N$ (gender, male\%) & $310(47.4 \%)$ & & & & \\
Age & 6.6 & 0.6 & 6.3 & 6.6 & 6.9 \\
BWT & 23.8 & 3.3 & 22.0 & 23.4 & 24.5 \\
Height & 1.22 & 0.07 & 1.18 & 1.22 & 1.26 \\
BMI & 16.0 & 2.2 & 14.4 & 15.7 & 17.2 \\
\hline
\end{tabular}

${ }^{a}$ Parameters for children from urban and non-urban groups were statistically equivalent

Parameters: mean, $N$ number of children, $S D$ standard deviation, Q25 and Q75 quartiles, $M E D$ median; age in years, $B W T$ body weight (kilograms), height (meter), $B M I$ body mass index

The first blood drop was removed from the skin, then, blood sample was taken directly into a plastic lithium heparinized microtube with a $200-\mu \mathrm{L}$ end-to-end capillary system (no. 077201, Kabe LaborTechnik, Numbrecht, Gernany). For each batch of samples, a blank microtube was added. The blood samples were frozen and kept at $-20^{\circ} \mathrm{C}$ until analysis.

Primary teeth were collected from children by their parents a few months before the date of delivery. Following the protocol, the parents have given an exact date of shed or extraction recorded for each tooth. In total, ca. 500 teeth were collected from 285 children. For study, 424 intact non-carious incisors were selected, designed, and qualified for study by a dental professional. In particular, number of included teeth was: central incisors, 132 upper and 150 lower and lateral incisors, 82 upper and 58 lower. The teeth were stored in paper envelopes in a desiccator until further processing.

\section{Chemicals and Solvents}

High-purity water obtained from a double-purification system Milli-RO and Milli-Q (Millipore, USA) was used for the final washing of vials and preparation or dilution of samples and standards. Nitric acid $65 \% \mathrm{HNO}_{3}$ (Suprapure, Merck, Germany) was used throughout the preparation of standards or samples. For method calibration, the standard solutions of 1,000 $\mathrm{mg} \mathrm{L}^{-1}$ were used (Merck, Pb, Cat. no. 19776; Cd, Cat. no. 19777; Zn, Cat. no. 19806). For routine quality control, the ICP Multi Element Standard I (toxic elements, No. 15474, Merck, Germany) was used. All final standard solutions for analysis were prepared in $0.5 \%$ nitric acid $(v / v)$. Washing solution for autosampler capillary was $0.2 \% \mathrm{w} / v$ aqueous solution of Triton X-100 (Merck, Germany) with the addition of $0.1 \% v / v$ nitric acid.

\section{Sample Preparation and Digestion}

Blood samples were analyzed directly after dilution with ammonium phosphate/EDTA/ Triton $\mathrm{X}-100 / \mathrm{HNO}_{3}$ modifier at a ratio of $1: 5$, and the same mixture was used for both $\mathrm{Cd}$ and $\mathrm{Pb}$ analysis. Matrix-assisted calibration curves were prepared from spiked bovine blood with both $\mathrm{Pb}$ and $\mathrm{Cd}$ standards at concentration range for environmental studies of 0 $4 \mu \mathrm{g} \mathrm{L}^{-1}$ for $\mathrm{Cd}$ and $0-240 \mu \mathrm{g} \mathrm{L}^{-1}$ for $\mathrm{Pb}$. The accuracy of the results was checked by means of the Certified Reference Material (CRM) reconstituted bovine blood BCR-194 (Community Bureau of Reference (BCR) in Brussels, Belgium). 
Quality control of the laboratory method for blood $\mathrm{Pb}$ and $\mathrm{Cd}$ testing (environmental level) was accomplished by participation in the control program by Institute and OutPatient Clinic for Occupational, Social and Environmental Medicine, University of Erlangen-Nuremberg, Germany, and in $\mathrm{CDC}$ program for $\mathrm{Pb}$ (all environmental and occupational levels) by Centers for Disease Control, Laboratory Inter-comparison Program: Blood Lead Laboratory Reference System (currently LAMP), Atlanta, USA.

Scalp hair samples were collected and washed according to International Atomic Energy Agency protocol recommended for environmental studies [36]. Briefly, hair samples were collected from a few places of the back scalp (ca. 0.1-0.2 g for small children study). The samples were placed in a 50-mL acid-precleaned glass beaker, covered with a clock glass slide, washed, 10 min each treatment, with $10 \mathrm{~mL}$ portion of acetone, three times with deionized water, and finally, with acetone, dried at room temperature, and then at $105^{\circ} \mathrm{C}$ for $2 \mathrm{~h}$ in a dust-free clean laboratory oven, and cooled in desiccator for $30 \mathrm{~min}$. Weighted samples $(0.1 \mathrm{~g})$ were digested in $5-\mathrm{mL} 65 \%$ nitric acid using a closed microwave system (MDS 2000, CEM Corp., USA) running 3-step program (power in percent/pressure in PSI/ time in seconds/TAP, the upper pressure), (1) 80/50/600/200; (2) $100 / 100 / 630 / 200$; and (3) $100 / 150 / 700 / 500$. The mineralizates were placed in weighted $30-\mathrm{mL}$ polypropylene vials and diluted to $20 \mathrm{~mL}$ with water and weighted. The accuracy of results was checked by means of the Certified Reference Material human hair GBW 09101 (Institute of Geophysical and Geochemical Exploration Langfang, Shanghai, China) and CRM 397 (BCR, Community Bureau of Reference in Brussels, Belgium).

Intact non-carious deciduous teeth selected for analyses were hand-washed with distilled water, and finally, with deionized water using a new hard toothbrush, placed in hard polypropylene $7-\mathrm{mL}$ vials, dried for $2 \mathrm{~h}$ at $50^{\circ} \mathrm{C}$ and then for $24 \mathrm{~h}$ at $70^{\circ} \mathrm{C}$, weighted at $0.001 \mathrm{~g}$ accuracy, then digested by the addition of $0.5 \mathrm{~mL}$ of $65 \%$ nitric acid and standing at room temperature for at least 1 week. The partially dissolved samples were allowed to stand for a prolonged time or/and for an addition of $0.5 \mathrm{~mL}$ nitric acid and warming in a water bath. All volumes were adjusted to $5 \mathrm{~mL}$ with water before analysis.

Matrix-assisted standard addition calibration curve for teeth analysis was done by analyte standard spiking to the solution containing an amount of calcium phosphate $\left(\mathrm{Ca}_{3}\left(\mathrm{PO}_{4}\right)_{2}\right)$ equivalent to mean weight of teeth. Spiked concentration range was $0-10 \mu \mathrm{g} \mathrm{L}^{-1}$ for $\mathrm{Cd}$ and $0-100 \mu \mathrm{g} \mathrm{L}^{-1}$ for $\mathrm{Pb}$. The accuracy of analytical method was checked by means of the Bone Meal (SRM 1486, NIST, Glen Spectra Reference Materials) as a CRM.

\section{Analytical Characterization}

Analyses were performed with the use of atomic absorption spectrometer (5100ZL, PerkinElmer, USA) with hollow cathode lamps (HCL). Lead and cadmium concentrations were estimated by the flameless atomic absorption spectrometry (GF-AAS) with Zeeman background correction in transversely heated graphite tube with Lvov platform. Zinc was measured by flame injection atomic absorption spectrometry (FI-AAS).

Dry air from central system and argon grade 5.0 were used. For $\mathrm{Pb}$ and $\mathrm{Cd}$ analysis, the samples and modifiers were injected with the use of an AS-70 autosampler. Autosampler aspiration sequence in all methods included $2 \mu \mathrm{L}$ of washing solution $(0.2 \%$ Triton $\mathrm{X}-100$ and/or $0.1 \% \mathrm{HNO}_{3}$ ) aspired before all the others, modifiers and sample.

Peak area was measured as an analytical signal. Each sample was run in duplicate, and the mean of two successive results, provided that their relative standard deviation did not exceed $5 \%$, was accepted as an estimate. 
The non-linear curves were obtained within the calibration range. Quality control samples were run repeatedly after each five (GF-AAS) or ten (FI-AAS) samples analyzed. All measurements were further reprocessed by the post-measurement recalibration and numerical signal drift correction as described before [34].

Instrumental conditions included: $\mathrm{HCL}$, slit $0.7 \mathrm{~nm}$; wavelength, $283.3 \mathrm{~nm}$ for $\mathrm{Cd}$ and $283.3 \mathrm{~nm}$ for $\mathrm{Pb}$.

\section{Blood}

Modifier: $2 \mathrm{~g}$ of Triton $\mathrm{X}-100,2 \mathrm{~g}$ of monoammonium phosphate $\left(\mathrm{NH}_{4} \mathrm{H}_{2} \mathrm{PO}_{4}\right), 0.2 \mathrm{~g}$ of Triplex (EDTA), $0.5 \mathrm{~mL}$ of nitric acid $65 \%$, and water to final volume of $1,000 \mathrm{~mL}$.

Calibration standards were common for $\mathrm{Cd}$ and $\mathrm{Pb}$ analysis and were prepared from spiked blood with $\mathrm{Cd}$ and $\mathrm{Pb}$ within the range of $0-10 \mu \mathrm{g} \mathrm{Cd} \mathrm{L}{ }^{-1}$ and $0-240 \mu \mathrm{g} \mathrm{L}^{-1}$, respectively. Analyses were performed from the same prepared sample sequentially, first $\mathrm{Cd}$, then $\mathrm{Pb}$. Calibration standards and blood samples for measurement were prepared as follows: $300 \mu \mathrm{L}$ of modifier was placed in $0.5-\mathrm{mL}$ autosampler cup, and $60 \mu \mathrm{L}$ of blood was directly dispensed to solvent under layer and mixed with pipette. Injection volume was $20 \mu \mathrm{L}$.

\section{Cd in Blood}

Temperature program (temperature in degree Celcius /ramp time in seconds/hold time in seconds/argon flow in milliliters per minute) was as follows: 110/10/30/250 and 170/10/20/250 (drying), 250/10/30/250 (ashing), 550/10/30/250 (aerated ashing), 20/1/10/250 (cooling), 1,700/0/4/0 (atomization), 2,300/1/1/250 (cleaning), and 600/8/1/250 (user controlled end-cooling). Limit of detection (LOD) was $0.10 \mu \mathrm{g} \mathrm{L}^{-1}$, precision was $4.2 \%$, and for CRM - BCR-194: Cd obtained $0.41 \mu \mathrm{g} \mathrm{L}^{-1}$; certified $0.5 \mu \mathrm{g} \mathrm{L}^{-1}$ (or $0.20 \mu \mathrm{g} \mathrm{L}^{-1}$ after recertification) [37].

\section{$\mathrm{Pb}$ in Blood}

Temperature program (temperature in degree Celcius/ramp time in seconds/hold time in seconds/argon flow in milliliters per minute) was as follows: $110 / 10 / 20 / 250,250 / 30 / 10 / 250$, $450 / 20 / 10 / 250,550 / 10 / 30 / 250$ (aerated ashing), 20/1/10/250,1,700/0/3/0, 2,400/1/1/250, and $600 / 8 / 1 / 250$ (end-cooling). LOD was $1.5 \mu \mathrm{g} \mathrm{L}^{-1}$ blood, precision was $1.3 \%$, and for CRM BCR-194: Pb obtained $125 \pm 4 \mu \mathrm{g} \mathrm{L}^{-1}$; certified $126 \pm 4 \mu \mathrm{g} \mathrm{L}^{-1}$.

\section{Teeth and Hair}

1. Modifier P2: diammonium phosphate $\left(\mathrm{NH}_{4}\right)_{2} \mathrm{HPO}_{4}\left(80 \mathrm{~g} \mathrm{~L}^{-1}\right)$.

2. Modifier CP: calcium carbonate $\left(\mathrm{CaCO}_{3}, 3.9 \mathrm{~g}\right)$ and phosphoric acid $85 \%\left(\mathrm{H}_{3} \mathrm{PO}_{4}, 3 \mathrm{~g}\right)$ were mixed (molar ratio $3: 2)$, then nitric acid $65 \%(20 \mathrm{~mL}$ ) and water were added to make up to a total volume of $50 \mathrm{~mL}$.

3. Modifier PD: mixture of $\mathrm{Pd}\left(2 \mathrm{~g} \mathrm{Pd} \mathrm{L}{ }^{-1}\right.$ in $3 \% \mathrm{HNO}_{3}$ as nitrate, diluted palladium modifier, Merck) and $\mathrm{Mg}\left(10 \mathrm{~g} \mathrm{Mg} \mathrm{L}^{-1}\right.$, as magnesium nitrate hexahydrate, $\mathrm{Mg}$ $\left(\mathrm{NO}_{3}\right)_{2} \cdot 6 \mathrm{H}_{2} \mathrm{O}$, Suprapure, Merck) at a ratio of $1: 1$. 
4. Modifier MG: solution of magnesium nitrate hexahydrate $\left(10 \mathrm{~g} \mathrm{Mg} \mathrm{L}^{-1}, \mathrm{Mg}\right.$ $\left.\left(\mathrm{NO}_{3}\right)_{2} \cdot 6 \mathrm{H}_{2} \mathrm{O}\right)$.

Standard mixtures for calibration were prepared from modifier CP and metal standards at a ratio of 3:1 to make a solution equivalent to mineralizate from teeth with weight of $100 \mathrm{mg}$.

\section{Cd in Teeth}

The Autosampler aspiration sequence was as follows: washing solution $\left(0.1 \% \mathrm{HNO}_{3}\right.$ and $0.2 \%$ Triton X-100) $2 \mu \mathrm{L}$; modifier P2, $5 \mu \mathrm{L}$; calibration standard with modifier $\mathrm{CP}$ or tooth mineralizate, $25 \mu \mathrm{L}$.

Temperature program (temperature in degree Celcius/ramp time in seconds/hold time in seconds/argon flow in milliliters per minute) was as follows: 110/10/30/250 and 170/10/20/ 250 (drying), 250/10/30/250 (ashing), 550/10/30/250 (aeration), 20/1/10/250 (cooling), 1,700/0/4/0 (atomization), 2,400/1/1/250 (cleaning), and 600/8/1/250 (end-cooling). Calibration curve was prepared in the range of $0-10 \mu \mathrm{g} \mathrm{L} \mathrm{L}^{-1}$. LOD was $0.10 \mu \mathrm{g} \mathrm{L}^{-1}$, precision was $3.4 \%\left(2.5 \mu \mathrm{g} \mathrm{L}^{-1}\right)$ and recovery was $90-101 \%$.

\section{$\mathrm{Pb}$ in Teeth}

The Autosampler aspiration sequence was as follows: washing solution $0.1 \% \mathrm{HNO}_{3} / 0.2 \%$ Triton X-100, $2 \mu \mathrm{L}$; modifier PD, $5 \mu \mathrm{L}$; and modifier P2, $3 \mu \mathrm{L}$; calibration standard with modifier $\mathrm{CP}$ or tooth mineralizate, $20 \mu \mathrm{L}$. Temperature program (temperature in degree Celcius/ramp time in seconds/hold time in seconds/argon flow in milliliters per minute) was as follows: $110 / 10 / 20 / 250,250 / 30 / 10 / 250,450 / 20 / 10 / 250,550 / 10 / 30 / 250$ (aerated ashing), $900 / 20 / 10 / 250,20 / 1 / 10 / 250,1,800 / 0 / 3 / 0,2,450 / 1 / 1 / 250$ and 600/8/1/250 (cooling). Calibration range was $0-100 \mu \mathrm{g} \mathrm{\textrm {L } ^ { - 1 }}$, LOD was $1.8 \mu \mathrm{g} \mathrm{L}^{-1}$, precision was $2.9 \%$ (25 $\mathrm{g} \mathrm{L} \mathrm{L}^{-1}$ ) and CRM Bone Meal (SRM 1486, NIST, Glen Spectra, England) Pb obtained $1.26 \pm 0.09 \mu \mathrm{g} \mathrm{g}^{-1}$, certified $1.335 \pm 0.014 \mu \mathrm{g} \mathrm{g}^{-1}$.

\section{Cd in Hair}

The aspiration sequence was as follows: washing solution, $2 \mu \mathrm{L}$; modifier MG, $5 \mu \mathrm{L}$; modifier P2, $5 \mu \mathrm{L}$; sample/standard, $10 \mu \mathrm{L}$. Temperature program (temperature in degree Celcius/ramp time in seconds/hold time in seconds/argon flow in milliliters per minute) was as follows: $110 /$ 10/30/250 and 170/10/20/250 (drying), 250/10/30/250 (ashing), 20/1/10/250 (cooling), 1,700/ 0/4/0 (atomization), 2,300/1/1/250 (cleaning), and 600/8/1/250 (end-cooling). Calibration range was $0-10 \mu \mathrm{g} \mathrm{L}^{-1}$, LOD was $0.09 \mu \mathrm{g} \mathrm{L}^{-1}$, precision was $2.3 \%\left(2.5 \mu \mathrm{g} \mathrm{L}^{-1}\right)$, and CRM: GBW 09101. Cd obtained $0.085 \pm 0.008 \mu \mathrm{g} \mathrm{g}^{-1}$, certified $0.095 \pm 0.012 \mu \mathrm{g} \mathrm{g}^{-1}$. Human hair, BCR CRM 397: Cd obtained 0.510 $\pm 0.020 \mu \mathrm{g} \mathrm{g}^{-1}$, certified $0.521 \pm 0.024 \mu \mathrm{g} \mathrm{g}^{-1}$.

\section{$\mathrm{Pb}$ in Hair}

Injection volume was $20 \mu \mathrm{L}$ mineralizate in $\mathrm{HNO}_{3}$ without an additional modifier. Temperature program (temperature in degree Celcius/ramp time in seconds/hold time in 
seconds/argon flow in milliliters per minute) was as follows: 110/10/20/250, 250/30/10/ $250,450 / 20 / 10 / 250,20 / 1 / 10 / 250,1,700 / 0 / 3 / 0,2,400 / 1 / 1 / 250$, and $600 / 8 / 1 / 250$ (endcooling). Calibration range was $0-200 \mu \mathrm{g} \mathrm{L}^{-1}$, LOD was $0.5 \mu \mathrm{g} \mathrm{L}^{-1}$, precision was $1.5 \%$ (50 $\mu \mathrm{g} \mathrm{L}^{-1}$ ), CRM GBW 09101: Pb obtained 7.3 $\pm 0.4 \mu \mathrm{g} \mathrm{g}^{-1}$, certified 7.2 $\pm 0.7 \mu \mathrm{g} \mathrm{g}^{-1}$, and CRM, human hair, BCR 397: Pb obtained 32.0 $\pm 0.8 \mu \mathrm{g} \mathrm{g}^{-1}$, certified $33.0 \pm 1.2 \mu \mathrm{g} \mathrm{g}^{-1}$

\section{Zinc in Hair}

Flame injection method was applied at the following parameters: 10-cm long burner; wavelength, $213.9 \mathrm{~nm}$; slit, $0.7 \mathrm{~nm}$; flame gas/air/acetylene mixture at flow rate ratio (in liters per minute) of 10:2; aspiration flow rate was ca. $1 \mathrm{~mL} \mathrm{~min}^{-1}$; analytical signal, $3 \mathrm{~s}$ timeaveraged absorbance; measurement, three successive runs; estimation, duplicate successive measurements accepted if the relative standard deviation was below 5\%. Calibration range was $0-3 \mathrm{mg} \mathrm{Zn} \mathrm{L}{ }^{-1}$, LOD was $0.02 \mathrm{mg} / \mathrm{L}$, precision was $0.4 \%\left(1 \mathrm{mg} \mathrm{L}^{-1}\right)$, CRM Human hair, GBW 09101: Zn obtained $190 \pm 6 \mu \mathrm{g} \mathrm{g}^{-1}$, certified $189 \pm 8 \mu \mathrm{g} \mathrm{g}^{-1}$, and CRM Human hair, BCR 397: Zn obtained 195 $\pm 8 \mu \mathrm{g} \mathrm{g}^{-1}$, certified $199 \pm 5 \mu \mathrm{g} \mathrm{g}^{-1}$.

\section{Post-Measurement Data Processing}

The sensitivity of the analytical system was tracked during the analyses with a control standard which was measured every five (GF-AAS) or ten samples (FI-AAS).

The software-collected internal absorbance signals were subjected to the postmeasurement processing consisting of precise recalibration via the estimation of the analytical form of the calibration equation and next, the estimation of numerical time-run functions describing the measured signals of cyclic quality controls, which were obtained by fitting the polynomials or mixed expressions. The functions were further used for correction of the sensitivity drift by interpolation. The combination of recalibration equations led to final estimations, as described by Barton (2008) [38]. The whole numerical processing was smoothly performed with home-made macros to the commercial software.

\section{Calculations and Statistics}

Concentrations below the LOD were replaced for convenience by $1 / 2$ LOD values. Because the number of teeth from the children were different, for the purpose of the evaluations presented in this paper, mean element content in teeth in each child was calculated stepwisely, as mean for incisors of each type, then mean for lateral (upper and lower) and mean for central (upper and lower) teeth, and finally, mean tooth-lead concentrations (PBT) for child as mean of the resulted data pair.

Statistical evaluation was performed with Statistica for Windows (StatSoft, Inc.). Generally, the data were log-transformed for statistical evaluation, if not stated otherwise. Both non-parametric and parametric tests were applied, if necessary. The $t$ test or KruskalWallis analysis of variance and $\mathrm{chi}^{2}$ test were used, if applicable. All mean values were geometric means (GM) and/or medians (MED). The 95\% confidence interval (CI) was estimated from the distribution profile as a range estimated from geometric standard deviation coefficient $\left(\mathrm{SDg}=10^{\mathrm{SD} \log _{-} \text {values }}\right.$ ) and geometric mean, $\mathrm{GM} \times \mathrm{SDg}^{ \pm 1.96}$ or from frequencies as 2.5 and 97.5 percentiles. 


\section{Results}

Analyses of $\mathrm{Pb}$ and $\mathrm{Cd}$ in blood, hair, and teeth were performed using the GF-AAS technique with Zeeman background correction, and $\mathrm{Zn}$ in hair was measured by FI-AAS. The methods were validated by the certified reference materials. The results proved that the methods were accurate enough to be applied in the study of children exposure. The mean values for metal contents analyzed in hair, teeth, and capillary blood are given in Table 2 .

All parameters were calculated separately for two major sub-sites, i.e., urban (U) and non-urban (NU) areas. Statistical evaluation of elemental concentrations in blood did indicate differences between $\mathrm{U}$ and $\mathrm{NU}$ sites, for $\mathrm{Pb}$ or $\mathrm{Cd}$. In hair, for both these elements and zinc, the mean values were significantly higher for NU sites. In teeth, the obtained results indicated a significantly higher $\mathrm{Pb}$ levels in NU site, but no difference in Cd was noted.

The application of the Centers for Disease Control and Prevention's level of concern for environmental exposure of children to $\mathrm{Pb}$ equaling $100 \mu \mathrm{g} \mathrm{L}^{-1}$ in blood [30, 39], valid in the period of the study, indicated the exceedance of the above level in $5 \%$ of the population, both in $\mathrm{U}$ and NU sites. Similarly, $1 \mu \mathrm{g} \mathrm{Cd} \mathrm{\textrm {L } ^ { - 1 }}$ limit value suggested for children from German studies [7] exceeded in less than $16 \%$ of the study population.

Hair metal levels from current study are collected (Table 3) and compared with data from other studies.

The mean values for $\mathrm{Pb}$ and $\mathrm{Cd}$ are comparable in European countries. The urban Krakow data are well comparable with the results of a large study for German population. Rural sites in the United Arab Emirates [40] showed a lower hair lead concentration (PBH), while the values were significantly higher for urban sites of this petrol-specific industrial country. Some differences were observed in hair zinc concentration $(\mathrm{ZNH})$, specifically, the values in NU sites from our study were higher in contrast to the quite comparable $\mathrm{PBH}$ in urban site of Krakow to the values of other countries.

For better characterization of differences between environmentally related subgroups (NU vs. U), and likewise, between genders (i.e., male vs. female), the respective specificities (odds ratios) were collected (Table 4).

It appeared that $\mathrm{Pb}$ in hair was site-specific for boys (Table 4, odds ratio $\mathrm{NU} / \mathrm{U}$ ), for whom $\mathrm{Pb}$ hair in $\mathrm{NU}$ site was 1.55 times higher than in $\mathrm{U}$ site $(p=0.010) . \mathrm{Pb}$ in teeth and nearly borderline significance $\mathrm{Pb}$ in blood were specific for NU site in girls. Similarly, $\mathrm{Cd}$ and $\mathrm{Zn}$ in hair of girls were specific for NU site.

For gender specificity (Table 4, odds ratio M/F), all significant values for $\mathrm{Pb}$ were higher than unity. In particular, $\mathrm{Pb}$ in hair was 1.60 times higher for boys in NU site; in teeth, the ratios were higher regardless of the site, while in blood, $\mathrm{Pb}$ was 1.29 times higher for boys in $\mathrm{U}$ site. There was no difference between boys and girls for $\mathrm{Pb}$ hair in $\mathrm{U}$ site, while $\mathrm{Cd}$ in hair was found to be specifically higher for boys only from $U$ site $(p=0.019)$.

Analyses of other factors found to be effective in $\mathrm{Pb}$ and $\mathrm{Cd}$ level differentiation were collected (Table 5).

Overall effect of gender was significant in PBH and PBT, thus, some gender-specific effects observed for subfractions (Table 4) were blurred. The above parameters were significantly associated with cigarette smoking by parents. Cigarette smoking at home by residents is a typical factor associated mainly with exposure to $\mathrm{Cd}$; however, only a suggestive effect for $\mathrm{Cd}$ was found in rural group (Table 5 legend, odds ratio, 1.6; $p=0.06$ ).

A significant influence was also found for the habit to leave the place of residence by children for 2 weeks or longer at least once a year. This was associated with significantly decreased exposure in $\mathrm{Pb}$ and $\mathrm{Cd}$ in hair and $\mathrm{Pb}$ in teeth. 


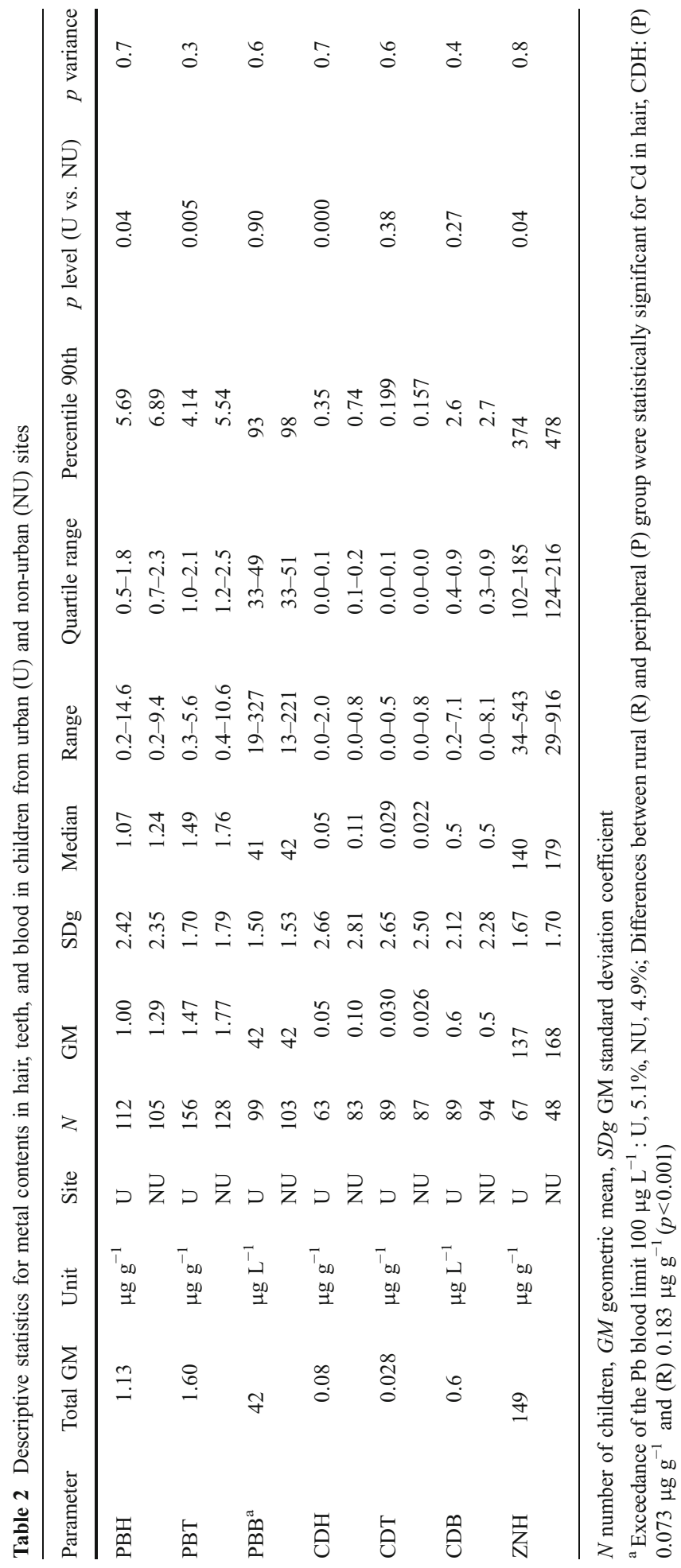


Table 3 Comparison of $\mathrm{Pb}$ and $\mathrm{Cd}$ content in hair of children in different studies

\begin{tabular}{llclllllll}
\hline Country & Site & Number & $\begin{array}{l}\text { Age } \\
\text { group }\end{array}$ & Period & PBH & CDH & ZNH & References \\
\hline Poland/Krakow & Urban & 163 & 6.4 & $1998-2001$ & 1.00 & 0.050 & 136 & This study \\
Poland/southern & Non-urban & 147 & 6.8 & $1998-2001$ & 1.28 & 0.094 & 166 & This study \\
Poland/Szczecin & Urban & 174 & & & 1.2 & 0.1 & {$[67]$} \\
Czech Rep. & General & 3,556 & 9.9 & $1994-2001$ & 1.6 & 0.14 & 124 & {$[68]$} \\
Germany & General & 711 & $6-14$ & $1991-1992$ & 1.02 & 0.048 & 141 & {$[7]$} \\
Italy & Towns & 193 & 13 & 2002 & $0.56-2.04$ & & & {$[41]$} \\
UAE & Urban; rural & 42 & $6-18$ & & U, 3.47; & & & {$[40]$} \\
& & & & & R, 0.79 & & & \\
\hline
\end{tabular}

$P B H \mathrm{~Pb}$ in hair, $C D H \mathrm{Cd}$ in hair, $Z N H \mathrm{Zn}$ in hair (in micrograms per gram), $U$ urban, $N U$ non-urban, $R$ rural site

An interesting significant effect in $\mathrm{Pb}$ and $\mathrm{Cd}$ hair was also found for a higher body mass index (BMI) of over 17 vs. children of BMI below 15. The effect is strongly genderspecific, as shown by data extension in Table 5 legend.

Finally, household drinking water hardness, expressed as a sum of concentration of $\mathrm{Ca}$ and $\mathrm{Mg}$ over $4 \mathrm{mM} \mathrm{L}^{-1}$, strongly increased in all metals in hair, but less for $\mathrm{Pb}$ and decreased $\mathrm{Cd}$ in teeth at near to borderline of significance.

The comparison of the relative content of $\mathrm{Pb}$ vs. $\mathrm{Cd}$ can differentiate typical and specific environmental exposure. The $\mathrm{Pb}$-to-Cd molar ratios in blood, hair, and teeth collected (Table 6) were calculated separately in U and NU sites and compared with the other studies.

The highest values were observed for blood. The values for hair were lower by an order of magnitude in comparison to teeth and blood. For teeth, the significant difference in $\mathrm{Pb}$ to-Cd ratio was observed between $\mathrm{U}$ and $\mathrm{NU}$ environments. Higher values for the later site were due to significantly higher $\mathrm{Pb}$ and somewhat lower $\mathrm{Cd}$ in teeth (Table 2). The ratios

Table 4 Odds ratios for element levels in hair, teeth, and blood of children for environments (NU vs. U site) and genders (male vs. female)

\begin{tabular}{|c|c|c|c|c|c|c|c|c|c|}
\hline \multirow[t]{3}{*}{ Element } & \multirow[t]{3}{*}{ Tissue } & \multicolumn{4}{|c|}{ Environmental specificity (NU/U) } & \multicolumn{4}{|c|}{ Gender specificity $(\mathrm{M} / \mathrm{F})$} \\
\hline & & \multicolumn{2}{|l|}{ M } & \multicolumn{2}{|l|}{$\mathrm{F}$} & \multicolumn{2}{|l|}{ NU } & \multicolumn{2}{|l|}{$\mathrm{U}$} \\
\hline & & Ratio & $p$ level & Ratio & $p$ level & Ratio & $p$ level & Ratio & $p$ level \\
\hline \multirow[t]{3}{*}{ PB } & Hair & 1.55 & 0.010 & 1.12 & & 1.60 & 0.005 & 1.16 & \\
\hline & Teeth & $1.19^{*}$ & 0.08 & 1.28 & 0.006 & 1.24 & 0.036 & 1.34 & 0.000 \\
\hline & Blood & $0.88^{* *}$ & 0.15 & $1.16^{*}$ & 0.052 & 0.97 & & 1.29 & 0.002 \\
\hline \multirow[t]{3}{*}{$\mathrm{CD}$} & Hair & $1.47^{* *}$ & 0.12 & 2.54 & 0.000 & 1.05 & & 1.82 & 0.019 \\
\hline & Teeth & 0.90 & & 0.78 & & 1.33 & 0.2 & 1.16 & \\
\hline & Blood & 0.79 & & 0.99 & & 1.08 & & $1.34^{*}$ & 0.06 \\
\hline $\mathrm{ZN}$ & Hair & 1.05 & & 1.40 & 0.031 & $0.85^{* *}$ & 0.2 & 1.13 & \\
\hline
\end{tabular}

Ratio odds ratio of GMs, ratio of GMs for subgroups, $p$ level $t$ test for comparison of independent groups (in $\log$ values), $P B$ lead, $C D$ cadmium, $Z N$ zinc, $M$ male, $F$ female

$p<0.05,{ }^{*} p<0.1,{ }^{* *} p<0.2$; for $p>0.2, p$ value is not given 
Table 5 Some other factors affecting exposure to $\mathrm{Pb}$ and $\mathrm{Cd}$ in hair, teeth, and blood for total group

\begin{tabular}{|c|c|c|c|c|c|c|c|c|c|c|}
\hline \multirow[t]{2}{*}{ Parameter } & \multicolumn{2}{|c|}{ Gender (M/F) } & \multicolumn{2}{|c|}{$\begin{array}{l}\text { Cigarette smoking } \\
\text { (yes/no) }\end{array}$} & \multicolumn{2}{|c|}{ Trips (yes/no) } & \multicolumn{2}{|c|}{ BMI (high/low) } & \multicolumn{2}{|c|}{$\begin{array}{l}\text { Water hardness } \\
\text { (high/low) }\end{array}$} \\
\hline & $\begin{array}{l}\text { Odds } \\
\text { ratio }\end{array}$ & $p$ level & $\begin{array}{l}\text { Odds } \\
\text { ratio }\end{array}$ & $p$ level & $\begin{array}{l}\text { Odds } \\
\text { ratio }\end{array}$ & $p$ level & $\begin{array}{l}\text { Odds } \\
\text { ratio }\end{array}$ & $p$ level & $\begin{array}{l}\text { Odds } \\
\text { ratio }\end{array}$ & $p$ level \\
\hline $\mathrm{PBH}$ & 1.3 & 0.017 & 1.4 & 0.005 & 0.7 & 0.008 & $1.5^{\mathrm{a}}$ & 0.017 & 1.4 & 0.07 \\
\hline PBT & 1.2 & 0.001 & 1.2 & 0.003 & 0.8 & 0.018 & 1.1 & 0.2 & & \\
\hline PBB & 1.1 & 0.06 & & & 0.9 & 0.2 & $1.1^{\mathrm{b}}$ & & & \\
\hline $\mathrm{CDH}$ & 1.3 & 0.1 & $1.3^{\mathrm{c}}$ & 0.2 & 0.6 & 0.002 & $1.8^{\mathrm{d}}$ & 0.019 & 2.4 & 0.002 \\
\hline CDT & 1.2 & 0.2 & & & & & & & 0.6 & 0.07 \\
\hline $\mathrm{CDB}$ & 1.2 & 0.08 & & & & & 1.3 & 0.2 & & \\
\hline $\mathrm{ZNH}$ & & & & & & & & & 1.5 & 0.002 \\
\hline
\end{tabular}

Trips out of place of residence for at least 2 weeks a year; gender: male(M) vs. female(F); cigarette smoking by at least one of the parents; BMI high $>17$ vs. BMI low $<15$; household drinking water hardness as molar sum of calcium and magnesium of above $4 \mathrm{mM} / \mathrm{L}$ vs. below $1.2 \mathrm{mM} / \mathrm{L}$; for $p>0.2, p$ value is not given

${ }^{\text {a }}$ Odds ratio: $\mathrm{PBH}$, male 1.3 n.s., female $1.6 p=0.016$

${ }^{\mathrm{b}} \mathrm{PBB}$, male, $1.3(p=0.06)$

${ }^{\mathrm{c}}$ for rural $(\mathrm{R})$ site, odds ratio was $1.6(p=0.06)$

${ }^{\mathrm{d}} \mathrm{CDH}$, male, 2.6; $p=0.018$, female 1.3 n.s.

calculated for other countries from literature data were comparable to the present study (Table 6).

More information about elements' relationships can be derived from correlations. Pearson product correlation coefficients with division into $U$ and NU sites were collected (Table 7).

Most coefficients are similar for both sites, and correlations for $\mathrm{Pb}$ are comparable. Positive correlations between $\mathrm{Pb}$ and $\mathrm{Cd}$ in the same and different tissues were widespread $(r=0.23-0.68)$. Particularly, correlation for $\mathrm{Pb}$ in blood and teeth reprocessed by the log-linear regression model and after exclusions of outliers was highly significant $(r=0.65, p<0.001)$, as

Table $6 \mathrm{~Pb}$-to-Cd molar ratios $(\mathrm{Pb} / \mathrm{Cd})$ for hair, teeth, and blood in the present and other studies

\begin{tabular}{|c|c|c|c|c|c|c|c|c|c|}
\hline \multirow[t]{2}{*}{ Sample } & \multicolumn{5}{|c|}{ Present study } & \multicolumn{4}{|l|}{ Other studies } \\
\hline & Site & GM & Median & $N$ & SDg & Environment & $\mathrm{Pb} / \mathrm{Cd}$ & Age or type & Reference \\
\hline \multirow[t]{3}{*}{ Hair } & $\mathrm{U}$ & 8.5 & 8.5 & 63 & 2.17 & U; R (Germany) & 11.5 & $6-18$ & [7] \\
\hline & NU & 7.1 & 7.5 & 83 & 2.23 & & & & \\
\hline & & $p=0.19$ & & & & & & & \\
\hline \multirow[t]{3}{*}{ Teeth } & $\mathrm{U}$ & 25 & 24 & 89 & 2.07 & U; R (Finland) & 15 & primary teeth & [69] \\
\hline & NU & 35 & 36 & 88 & 2.12 & & & & \\
\hline & & $p=0.002$ & & & & & & & \\
\hline \multirow[t]{3}{*}{ Blood } & $\mathrm{U}$ & 68 & 65 & 88 & 1.92 & U; R (Germany) & U $125 ; \mathrm{R} 68$ & $6-18$; adults & {$[7]$} \\
\hline & NU & 83 & 78 & 94 & 2.08 & F; M (Krakow) & F 74; M 91 & 11 & {$[58]$} \\
\hline & & $p=0.06$ & & & & & & & \\
\hline
\end{tabular}

$G M$ geometric mean, $N$ number of cases, $S D g$ geometric standard deviation, $p$ level from $t$ test for independent samples, $H$ hair, $T$ teeth, $B$ blood; $M$ male, $F$ female; $U$ urban; $N U$ non-urban, $R$ rural 
Table 7 Pearson product correlation coefficients for log-transformed $\mathrm{Pb}$ and $\mathrm{Cd}$ contents in hair, teeth, and blood of children from $\mathrm{U}$ and NU sites

\begin{tabular}{lccccccc}
\hline U group & PBH & PBT & PBB & CDH & CDT & CDB & ZNH \\
\hline PBH & - & 0.30 & 0.23 & 0.69 & $0.26^{*}$ & 0.26 & -0.24 \\
PBT & 0.30 & - & 0.40 & 0.39 & 0.65 & 0.23 & \\
PBB & 0.23 & 0.40 & - & 0.32 & $0.27^{*}$ & 0.54 & \\
CDH & 0.69 & $0.39^{*}$ & 0.32 & - & $0.22^{* *}$ & & $-0.26 ! !$ \\
CDT & $0.26^{*}$ & 0.65 & $0.27^{*}$ & $0.22^{* *}$ & - & & \\
CDB & 0.26 & 0.23 & 0.54 & & & - & \\
ZNH & -0.24 & & & $-0.26^{* *}$ & & & - \\
NU group & PBH & PBT & PBB & CDH & CDT & CDB & ZNH \\
PBH & - & 0.30 & 0.39 & 0.66 & & 0.21 & \\
PBT & 0.30 & - & 0.38 & $0.18^{* *}$ & 0.63 & 0.32 & \\
PBB & 0.39 & 0.38 & - & & & 0.52 & \\
CDH & 0.66 & $0.18^{* *}$ & & - & & & $0.39^{*}$ \\
CDT & & 0.63 & & & & & \\
CDB & 0.21 & 0.32 & 0.52 & & & & - \\
ZNH & & & & $0.39 *$ & & & \\
\hline
\end{tabular}

Correlation coefficients included at $p<0.05$ or ${ }^{*} p<0.1$ or ${ }^{* *} p<0.2$; correlations at $p>0.2$ were omitted

shown in Fig. 1. According to the regression equation, $\mathrm{Pb}$ blood, $100 \mu \mathrm{g} \mathrm{L}{ }^{-1}$, referred to 2.6 (1.2-5.9) $\mu \mathrm{g} \mathrm{g}^{-1} \mathrm{~Pb}$ in teeth $(95 \% \mathrm{CI})$, while $35 \mu \mathrm{g} \mathrm{L}^{-1}$ referred to $1.2(0.6-2.8) \mu \mathrm{g} \mathrm{g}^{-1} \mathrm{~Pb}$ in teeth. Predictability for exceeding $\mathrm{Pb}$ teeth, $2.6 \mu \mathrm{g} \mathrm{g}^{-1}$, was $14 \%$ vs. $5 \%$ for $\mathrm{Pb}$ blood reference limit.

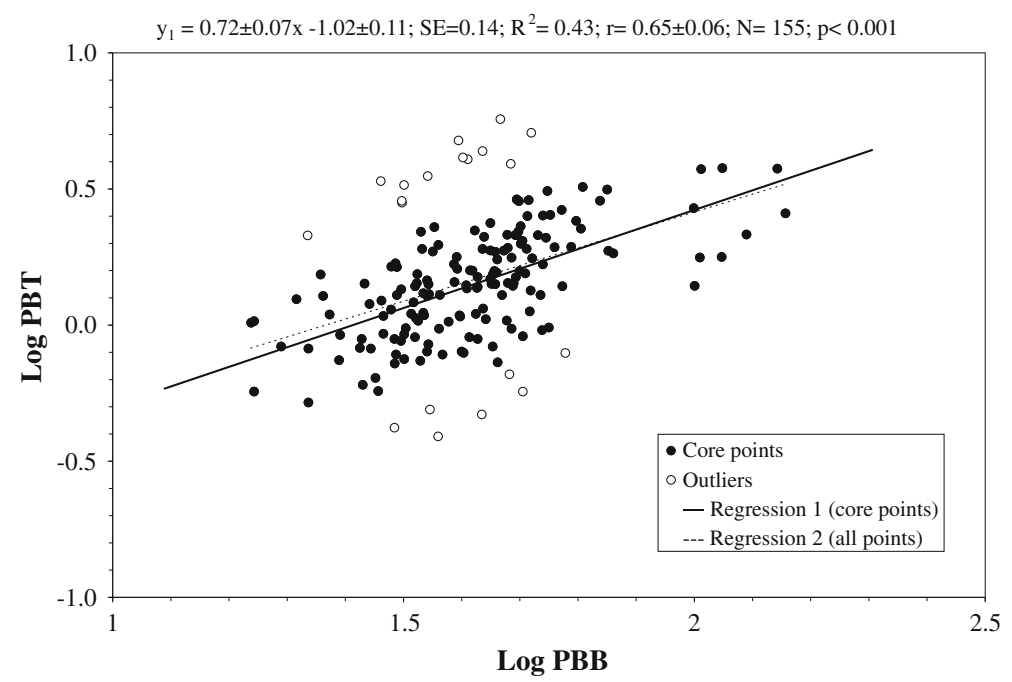

Fig. 1 Significant positive correlation between lead concentration in blood (PBB) and teeth (PBT) of children (logarithmic values). Regression for core points without outliers (1, spots) is shown as a thick line and regression parameters are given in the inset. Regression for all points (2) is shown as a dashed line 
There was no significant correlation for $\mathrm{Pb}$ in blood and hair. For $\mathrm{Cd}$, there was no significant correlation between any of the tissues investigated, except for a suggestive one, of borderline significance for hair and teeth in $U$ site $(r=0.23, p<0.1)$.

There are also some specific correlations for zinc which need some attention. Hair zinc showed weak insignificant correlations with $\mathrm{Cd}$ in hair, a positive correlation in NU site, and a negative one in U site. For hair zinc and lead, a significant negative correlation was found in $\mathrm{U}$ site. The negative association between $\mathrm{Zn}$ and $\mathrm{Pb}$ in hair of children was further enforced after exclusion outliers over 2SD. The resulted linear regression at correlation coefficient -0.68 is shown in Fig. 2.

\section{Discussion}

The major question to be addressed in this paper is the validity of a non-invasive biological material of children, especially teeth and hair, for evaluation of environmental exposure and potential body burden of the two most toxic elements, $\mathrm{Pb}$ and $\mathrm{Cd}$, in 6-year-old children.

Since many years, analyses of hair, primary and permanent teeth, and nails have been attractive and have been paid much attention as non-invasive methods allowing for the large-scale environmental exposure monitoring of children and adults. However, urine and blood metal levels and health status indices were finally claimed conclusive. $\mathrm{Pb}$ and $\mathrm{Cd}$ are distributed in the organism via some similar but also by different mechanisms. $\mathrm{Pb}$ is deposited largely in bones and bound in erythrocytes. From this point of view, the use of plasma for $\mathrm{Pb}$ monitoring seems to be restricted to protein-bound $\mathrm{Pb}$ fraction.

Cadmium has very high affinity for the major depository organs (kidney and liver), and this is what makes $\mathrm{Cd}$ blood levels a poor reflection of $\mathrm{Cd}$ body stores, and urine $\mathrm{Cd}$ appeared to be more adequate [17].

Hair has been considered to be suitable for comparative studies of environmental exposure of different age groups and populations [41]; however, metal levels measured can be an undefined and non-uniform combination of endogenous and exogenous metal

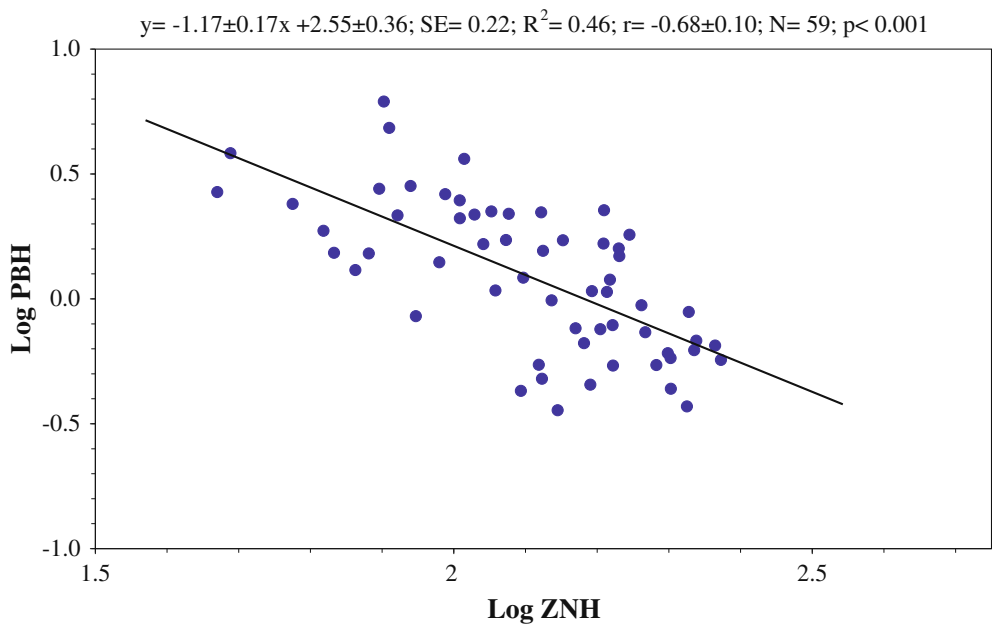

Fig. 2 Significant negative correlation between lead $(\mathrm{PBH})$ and zinc $(\mathrm{ZNH})$ in hair of children from urban site (logarithmic values) 
amounts, depending on washing methods applied before analysis [42]. These complications make methods' standardization difficult, increase variability of results, and cause problems with interpretation [28]. The CDC expert advisory panel, recently established to review current knowledge about the use of hair for trace metal analysis in bio-monitoring [43], has concluded that currently there is no adequate knowledge on the use of the results of hair analysis for evaluation of exposure, and adequate baseline or background values for populations are still lacking.

Teeth are believed to be least dependent on exogenous pollution of biological material [44]. Especially primary teeth of small children are attractive due to easiness of sample collection via the least invasive extraction and natural shedding.

In typical urban or sub-urban environment, anthropogenic $\mathrm{Pb}$ and $\mathrm{Cd}$ generally come to human organism together, from the same sources, like airborne particles from fumes, dust, soil, and drinking water. For localities close to specific industries or deposits, the proportion of both toxic elements can be changed. Geographical gradients of human exposure, for example between urban and rural populations, were observed in a variety of studies $[45,46]$. Seasonal fluctuations of $\mathrm{Pb}$ concentration in the blood of children [22] and correlation with low soil moisture suggested that the main $\mathrm{Pb}$ exposure was from inhalation and ingestion of soil and dust. Hence, the lead accumulated in the soil profile can be a major source of $\mathrm{Pb}$ for humans even years after termination of leaded gasoline usage [47]. The German environmental study (1982-1986) indicated the decrease in PBT levels following the decrease in children's exposure [48]. The study of $\mathrm{Pb}$ isotope ratios demonstrated an association between $\mathrm{Pb}$ in airborne particulate matter (PM) and hair of children, suggesting that $\mathrm{PM}$ was a major $\mathrm{Pb}$ source in children's hair in the study area [25]. This was probably associated with predominant low emission from household stoves and industrial emission at that period.

There are studies which have elucidated that there exist correlations between the elevated $\mathrm{Pb}$ levels in teeth and development of arteriosclerosis in Finnish children [49] and chronic renal failure in children [50]. The recent studies in adults showed that high PBT levels might be related with diabetes and hypertension [51]. It was also found that high blood lead (PBB) and PBH was associated with breast cancer [52].

\section{Exposure of Children}

The overall $\mathrm{Pb}$ and $\mathrm{Cd}$ levels in hair of children found in our study are comparable to the data found for other Polish cities and European countries, i.e., Germany, Czech Republic, and Italy (Table 3). Hair cadmium levels in Krakow were similar to those in Germany (the country sharing the same latitude) and somewhat lower than in other countries.

The same is true also for zinc in hair $(\mathrm{ZNH})$ for $U$ site in our study, while in NU site, $\mathrm{ZNH}$ was found to be higher. Possibly, some environmental factors can influence this difference, and this can be, for instance, substantially higher $\mathrm{Zn}$ in drinking water found in NU [33].

In teeth, $\mathrm{Pb}$ levels found here were comparable with those in some other countries, e.g., Turkey (former, $3.42 \mu \mathrm{g} \mathrm{g}^{-1}$ [53]; recent, 1.30-1.77 $\mathrm{\mu g} \mathrm{g}^{-1}$ [54]), and non-polluted regions of Brasilia $\left(1.3 \mu \mathrm{g} \mathrm{g}^{-1}\right)$ [55], while enhanced $\mathrm{Pb}$ and $\mathrm{Cd}$ teeth levels were observed in children from heavy industrial area of southern Poland [56].

Environmental effect can be discussed here on the basis of comparisons between $U$ and NU sites in our study. This investigation showed that the contents of all elements in hair of children were repeatedly higher in non-urban sites (Table 2). This effect was also found 
significant for PBT $(p=0.004)$. This environmentally specific effect was further expressed as odds ratio for NU vs. $\mathrm{U}$ site for each gender group (Table 4). It showed that $\mathrm{Pb}$ was specific for environment only in hair for boys, and not for girls. For PBT, there was a suggestive difference for boys, while a highly significant effect was seen in the case of girls. The same was observed also for cadmium in hair (CDH) and ZNH levels. For girls, a suggestive influence of environment was also found for $\mathrm{Pb}$ in blood. All the above effects suggested a higher children exposure to $\mathrm{Pb}$ in the non-urban environment. The non-urban site in our study consists of sub-urban areas of Krakow and surroundings, and two rural sites in southeast area. They were combined into one site because no differences in $\mathrm{Pb}$ and $\mathrm{Cd}$ were observed in previous studies [34, 57], and this was confirmed by the lack of differences between these sites for the biological materials (Table 2).

The above observations are in contrast with the lower $\mathrm{Pb}$ levels expected in non-industrial rural areas. There are two possible explanations for this observation. First, the environmental pollution in urban Krakow is low, suggested by low PBH and CDH levels. Second, there is pollution in NU sites due to local specific sources. These may be, e.g., non-restricted coal use producing low emission and residues from leaded gasoline deposits in the households' neighborhood due to car maintenance and repair. The origin of $\mathrm{Pb}$ in hair from ambient sources is suggested by the higher $\mathrm{PBH}$ in boys, who are more physically active outside households than girls. In agreement with this interpretation, $\mathrm{CDH}$ and $\mathrm{ZNH}$ in girls were higher in NU, while PBH was the same in both sites (Table 4, PBH, NU/U odds, F 1.12, n.s.).

Gender specificity given as the odds ratio in Table $4(\mathrm{M} / \mathrm{F}$ parameters) confirmed that environmental exposure was greater in NU boys than in girls taking into consideration PB in hair $(\mathrm{H})$, while if teeth $(\mathrm{T})$ were analyzed, the same effect was observed regardless of the environment. Gender-specific exposure to $\mathrm{Pb}$ (or accumulation) and stronger effect in boys were evident in PB blood in urban site (PBB), and suggestive of the same for CDB (Table 4). A similar observation has been reported by Huzior-Balajewicz et al. (2001) [58] for lead in the study of 11-year-old children from the suburban areas of Krakow, in which they found that boys accumulated more lead whereas the girls absorbed more cadmium. Gender-specific accumulation of $\mathrm{Pb}$ was observed in some studies in permanent teeth [59]; however, the other studies have not revealed such differences in primary teeth, e.g., [54, 60].

In addition to obvious effect of the environmental pollution level, both these abovediscussed alternative approaches strongly suggest that the exposure of children seems to be related to behavioral factors. It can be related, for instance, to a proportion of the activity outside and inside the households, which could be deduced from the above gender and environmental specificities observed. A strong influence of household pollution, related to parents' occupation, was evident from studies of workers of metal industry and mining performed by Chiaradia et al. [61].

The above suggestion was also supported in this study by the analysis of the exposure to $\mathrm{Pb}$ and $\mathrm{Cd}$ in relation to some other factors which are given in Table 5. It was found that seasonal leaving of the place of residence (holiday and weekend trips) to environmentally cleaner areas was a factor associated with significant $\mathrm{PBH}, \mathrm{CDH}$, and PBT lowering. This factor, however, may be a general indicator of pro-ecological awareness of children's parents and a combined effect of all pro-health behaviors of these families.

Additionally, this effect also suggests that a primary exposure factor of children seems to be related to the nearest neighborhood to households (place for physical activity of children) and the kind of occupational activity of the parents or adult residents in the private households. The above suggestion is also in accordance with the lack of differences between sub-urban and rural environments found here since private houses and estates are specifically major types of houses in these areas. 
The further effects are found in the analysis of some other factors (Table 5). Cigarette smoking by at least one of the parents was associated with the significant increase only of $\mathrm{Pb}$ in hair and teeth. This is surprisingly converged with the gender effect on exposure to $\mathrm{Pb}$, suggesting that preference for this habit by family members at householders may make children, especially boys, passive smokers.

The next interesting observation from this analysis entails the association between $\mathrm{PBH}$ (or similarly $\mathrm{CDH}$ ) levels and BMI (Table 5). In particular, at higher BMI, the increased PBH was specific for girls (odds ratio, 1.6; $p=0.016$ ), while CDH was specific for boys (odds ratio, 2.6; $p=0.018$ ). The other authors also found that the concentrations of cadmium in the hair and BMI showed a positive correlation [62].

Finally, significant enhancement of all metal levels in hair was observed at high concentration of minerals in household drinking water $(\mathrm{Ca}$ and $\mathrm{Mg})$, termed hardness in Table 5. This effect was especially strong for cadmium (odds, $2.4 ; p=0.002$ ), zinc (odds, $1.5 ; p=0.002$ ) while it is suggestive for $\mathrm{Pb}$ (odds, 1.4). The interesting opposite weak association for Cd teeth (odds, 0.6) needs further studies. The aforementioned effects can be due to the water corrosiveness in zinc-platted pipelines, which will be elucidated elsewhere.

\section{Correlations}

As a preliminary step in the analysis of relationships between metal contents, the $\mathrm{Pb}$-to-Cd ratios were calculated, separately for $U$ and NU sites (Table 6). In general, the differences in $\mathrm{Pb}$-to-Cd ratio between $\mathrm{U}$ and $\mathrm{NU}$ sites were not substantial. This suggests a similar pattern of pollution in these environments. The only significant difference was the higher $\mathrm{Pb}$-to-Cd ratio for teeth of children from NU site $(p=0.002)$, which seems to be a consequence of differences in $\mathrm{Pb}$ in teeth $(p=0.004)$ because the levels for $\mathrm{Cd}$ are statistically indistinguishable (Table 2$)$.

$\mathrm{Pb}$-to-Cd molar ratio in airborne particulate matter PM2.5 in the same area (and period) as in the current study was similar even for larger particles like PM10 [25]. Thus, relative hair metal contents did not follow directly the airborne pattern. The lower hair $\mathrm{Pb}$-to-Cd ratio indicates more effective cadmium accumulation in hair over lead or less $\mathrm{Pb}$. For teeth and blood, the ratio values were higher than those in hair and in the environment. The higher $\mathrm{Pb}$-to-Cd ratio in teeth and blood seems to be consistent with stronger biological filters for cadmium in the human body, over the lead, which was deduced above. The above parameter ( $\mathrm{Pb}$-to-Cd ratio) can thus be more useful for the comparison of the same kind of samples.

Pearson product correlations for all elements and tissues investigated (Table 7), analyzed separately, both for U and NU sites, indicated several common and significant, mostly positive, associations between elements, at majority similar for both sites. Those of great importance include the especially evident correlation between $\mathrm{Pb}$ in the blood and teeth $(r=0.40$ and 0.38 , for $\mathrm{U}$ and NU site, respectively) and between $\mathrm{Pb}$ in blood and hair $(r=0.23$ and 0.39 , for $\mathrm{U}$ and NU site, respectively). The significant correlations found for two different investigated sites support these associations more strongly than the correlation for the combined total population studied. However, for the latter case, they were similarly significant. The $\mathrm{Pb}$ teeth level $\left(2.6 \mu \mathrm{g} \mathrm{g}^{-1}\right)$ associated with Pb blood $100 \mu \mathrm{g} \mathrm{L}^{-1}$ estimated via log-linear regression (Fig. 1) can be considered as reference value for $\mathrm{Pb}$ data evaluation with the teeth analysis. Predictability for exceeding $\mathrm{Pb}$ teeth $2.6 \mu \mathrm{g} \mathrm{g}^{-1}$ was higher by about $10 \%$ than for $\mathrm{Pb}$ blood reference limit. More rigorous teeth cut-off limit, however, is partially counterbalanced by rather wide confidence ranges for $\mathrm{Pb}$ teeth. Moreover, the presence of some outliers over and under regression area suggests that once measured, $\mathrm{Pb}$ blood may not reflect long-term $\mathrm{Pb}$ accumulation, but rather, current level of exposure for some cases. Interestingly, the 
relationship between mean values for $\mathrm{Pb}$ content in blood and teeth from this study (42 $\mu \mathrm{g} \mathrm{L}^{-1}$ and $1.60 \mu \mathrm{g} \mathrm{g}^{-1}$, respectively, Table 2) is quite consistent with the data for German preschool children reported by Wineke et al. (1994), $50 \mu \mathrm{g} \mathrm{Pb} \mathrm{L}^{-1}$ and $2 \mu \mathrm{g} \mathrm{Pb} \mathrm{g}$ in blood and teeth, respectively. Apart from some limitations, however, the above correlation allows for evaluation of children's $\mathrm{Pb}$ accumulation over the childhood period via $\mathrm{Pb}$ teeth and classify roughly their exposure level. This can help to undertake further diagnostic direction or/and help to interpret later health effects in adolescence, which could be potentially associated with $\mathrm{Pb}$ exposure (or its lack) in preschool period.

The correlation between $\mathrm{Pb}$ blood and hair was positive and significant; however, no good linear regression could be derived. This is consistent with general problems associated with the interpretation of $\mathrm{Pb}$ in hair [27, 63]. For $\mathrm{Cd}$, there were no significant correlations between the tissues investigated, apart from correlation with hair $\mathrm{Pb}$. The later can be interpreted as a consequence of a common origin of both elements in children's environment. Strong correlations between $\mathrm{Cd}$ and $\mathrm{Pb}$ were also observed in other studies [64]. Thus, these seem to reflect, in general, the current technology profile and related pollution in the world. One may emphasize that $\mathrm{Pb}$ in hair is strongly correlated also with $\mathrm{Zn}$ (negative effect), as found here, as well as with many other metals, as shown in the other studies, e.g., [27]. These suggest that relative parameters can be more useful instead of element contents. Considering the possible external contribution of both metals, these observations taken together suggested that direct interpretation of hair $\mathrm{Pb}$ levels is difficult and of poor prognostics for the future.

The CDC working group's report called for further studies to examine the relationship between lower $\mathrm{Pb}$ blood levels and health outcomes to provide a more complete understanding of this issue which is especially important in children [65], and this has been recently summarized [63]. Thus, the correlations found here fit well to the above calls and support the usefulness of primary teeth (and possibly hair in the future) for $\mathrm{Pb}$ bio-monitoring or for support in diagnostics in developing organism of children during teenage period.

Another finding of this study, mentioned above, is the negative correlation observed between zinc and lead in hair for $\mathrm{U}$ site and a positive correlation of $\mathrm{Zn}$ and $\mathrm{Pb}$ in $\mathrm{NU}$ site. Despite the fact that these two correlations seem to be contradicting, they may suggest that zinc appears to show a double mode of interaction with lead in hair. At a low $\mathrm{ZNH}$ concentration observed in $\mathrm{U}$ site, it correlates negatively with $\mathrm{PBH}$, possibly via competition, and this effect was highly significant (Fig. 2). At a higher ZNH found for children from NU, this correlation became not significant. However, a positive correlation of $\mathrm{ZNH}$ was observed with $\mathrm{CDH}$. A positive correlation between $\mathrm{CDH}$ and $\mathrm{PBH}$ suggested the presence of an independent mode of their binding to hair, related probably to higher availability from environment. In other words, biologically controlled competitive $\mathrm{Pb}$ and $\mathrm{Zn}$ binding at specific hair sites became out-of-control (or an opposite direction) on metal overload, thus, abolishing (or makes random) observed primary effect. The same can be true for $\mathrm{Cd}$. This is supported by the observation that low and high dietary $\mathrm{Zn}$ interacted with accumulation of lead and caused different effects on bones in growing rats [66]. At some exception for $\mathrm{Pb}$, these three metals $(\mathrm{Pb}, \mathrm{Cd}$, and $\mathrm{Zn})$ are closely associated with common anthropogenic sources. These were observed, for example, for household drinking water [33] and that may have an effect to some extent on the associations observed in hair.

\section{Conclusions}

The widespread positive correlations found between $\mathrm{Pb}$ and $\mathrm{Cd}$ in blood, hair, and primary teeth suggested a common anthropogenic origin of these elements at the children's 
environment studied. Strong correlations found in this study for $\mathrm{Pb}$ in blood and primary teeth in 6-year-old children support the applicability of primary teeth for bio-monitoring of environmental $\mathrm{Pb}$ exposure of children at preschool period. One may suggest to consider an analysis of at least one primary tooth of a child for $\mathrm{Pb}$ before the school period. Primary teeth analysis can be of supporting value for health diagnostic during the adolescence, and this advantage should be popularized. For exposure to $\mathrm{Cd}$, the presented results are suggestive, but more studies are needed. The interpretation of $\mathrm{Pb}$ in hair seems to be difficult due to several factors involved, including between-elements' interactions and external contamination. The observed associations of exposure with behavioral and environmental factors suggested high sensitivity of the biological materials studied for ambient factors, thus, they should be included in studies. Finally, the observations in this study suggest that the role of zinc and its possible potential to exacerbate accumulation of cadmium and especially lead, seems to be underappreciated and needs more attention in further studies.

Acknowledgement The author thanks Ms. Maria Folta for analytical assistance, students of the Jagiellonian University for sample collection and some laboratory operations, and Dr. Elżbieta Pisarska for evaluations of collected teeth. Prof. dr hab Zofia Zachwieja is acknowledged for the interesting and stimulative discussions.

Competing interest None.

Open Access This article is distributed under the terms of the Creative Commons Attribution Noncommercial License which permits any noncommercial use, distribution, and reproduction in any medium, provided the original author(s) and source are credited.

\section{References}

1. Horiguchi H, Oguma E, Sasaki S et al (2005) Environmental exposure to cadmium at a level insufficient to induce renal tubular dysfunction does not affect bone density among female Japanese farmers. Environ Res 97:83-92

2. Franzaring J, Holz I, Zipperle J, Fangmeier A (2010) Twenty years of biological monitoring of element concentrations in permanent forest and grassland plots in Baden-Württemberg (SW Germany). Environ Sci Pollut Res Int 17:4-12

3. Aberg GE (2001) Tracing pollution. Water, Air, and Soil Pollution 130:1577-1582

4. Bacon JR (2002) Isotopic characterisation of lead deposited 1989-2001 at two upland scottish locations. J Environ Monit 4:291-299

5. Jarosińska D, Muszyńska-Graca M, Dabkowska B et al (2003) Environmental lead exposure in Polish children: blood lead levels, major sources and principles of the lead poisoning prevention. Bioinorg Chem Appl 2003:333-342

6. Pan J, Plant JA, Voulvoulis N et al (2010) Cadmium levels in Europe: implications for human health. Environ Geochem Health 32(1):1-12

7. Seifert B, Becker K, Helm D et al (2000) The German Environmental Survey 1990/1992 (GerES II): reference concentrations of selected environmental pollutants in blood, urine, hair, house dust, drinking water and indoor air. J Expo Anal Environ Epidemiol 10:552-565

8. Schulz C, Angerer J, Ewers U et al (2009) Revised and new reference values for environmental pollutants in urine or blood of children in Germany derived from the German Environmental Survey on Children 2003-2006 (GerES IV). Int J Hyg Environ Health 212:637-647

9. Benoff S, Jacob A, Hurle IR (2000) Male infertility and environmental exposure to lead and cadmium. Hum Reprod Update 6:107-121

10. Hartwig A (2010) Mechanisms in cadmium-induced carcinogenicity: recent insights. Biometals 23 (5):951-960

11. ATSDR 2008. The agency for toxic substances and disease registry, Atlanta, Georgia. Toxicological profile for cadmium. Available: http://www.atsdr.cdc.gov/ToxProfiles/tp5.pdf 
12. Neri M, Ugolini D, Bonassi S et al (2006) Children's exposure to environmental pollutants and biomarkers of genetic damage. II. Results of a comprehensive literature search and meta-analysis. Mutat Res 612(1):14-39

13. Nawrot T, Plusquin M, Hogervorst J et al (2009) Environmental exposure to cadmium and risk of cancer: a prospective population-based study. Lancet Oncol 7:119-126

14. Jin YH, Clark AB, Slebos RJ et al (2003) Cadmium is a mutagen that acts by inhibiting mismatch repair. Nat Genet 34:326-329

15. Schoeters G, Den Hond E, Zuurbier M et al (2006) Cadmium and children: exposure and health effects. Acta Paediatr Suppl 95:50-54

16. Burbure C, Buchet JP, Bernard A et al (2003) Biomarkers of renal effects in children and adults with low environmental exposure to heavy metals. J Toxicol Environ Health A 66:783-798

17. Järup L, Hellström L, Alfvén T et al (2000) Low level exposure to cadmium and early kidney damage: the OSCAR study. Occup Environ Med 57:668-672

18. Järup L, Akesson A (2009) Current status of cadmium as an environmental health problem. Toxicol Appl Pharmacol 238:201-208

19. Suwazono Y, Uetani M, Akesson A et al (2010) Recent applications of benchmark dose method for estimation of reference cadmium exposure for renal effects in man. Toxicol Lett 198(1):40-43

20. ATSDR 2007. The agency for toxic substances and disease registry, Atlanta, Georgia. Toxicological profile for lead. Available: http://www.atsdr.cdc.gov/ToxProfiles/tp13.pdf

21. Winneke G, Altmann L, Kramer U et al (1994) Neurobehavioral and neurophysiological observations in six year old children with low lead levels in East and West Germany. Neurotoxicol 15(3):705-713

22. Ferré-Huguet N, Nadal M, Schuhmacher M et al (2009) Monitoring metals in blood and hair of the population living near a hazardous waste incinerator: temporal trend. Biol Trace Elem Res 128:191-199

23. Laidlaw MA, Mielke HW, Filippelli GM et al (2005) Seasonality and children's blood lead levels: developing a predictive model using climatic variables and blood lead data from Indianapolis, Indiana, Syracuse, New York, and New Orleans, Louisiana (USA). Environ Health Perspect 113:793-800

24. Anagnostopoulou MA, Day JP (2006) Lead concentrations and isotope ratios in street dust in major cities in Greece in relation to the use of lead in petrol. Sci Total Environ 367:791-799

25. Barton H, Zachwieja Z, D'Ilio S et al (2000) Application of routine estimation of Pb isotopic ratios by inductively coupled plasma mass spectrometry for studying the $\mathrm{Pb}$ origin in hair of children living in polluted areas. A pilot study. Microchem J 67:21-30. doi:10.1016/S0026-265X(00)00089-8

26. Flament P, Bertho ML, Deboudt K et al (2002) European isotopic signatures for lead in atmospheric aerosols: a source apportionment based upon $206 \mathrm{~Pb} / 207 \mathrm{~Pb}$ ratios. Sci Total Environ $296: 35-57$

27. ATSDR (2001). The Agency for Toxic Substances and Disease Registry, Atlanta, Georgia. Summary report on Hair analysis panel discussion exploring the state of the science. Available: http://www.atsdr. cdc.gov/HAC/hair_analysis/hair_analysis.pdf

28. Barbosa F Jr, Tanus-Santos JE, Gerlach RF et al (2005) A critical review of biomarkers used for monitoring human exposure to lead: advantages, limitations, and future needs. Environ Health Perspect 113:1669-1674

29. Binns HJ, Campbell C, Brown MJ et al (2007) Interpreting and managing blood lead levels of less than $10 \mathrm{microg} / \mathrm{dl}$ in children and reducing childhood exposure to lead: recommendations of the Centers for Disease Control and Prevention Advisory Committee on Childhood Lead Poisoning Prevention. Pediatrics 120:e1285-98. Available: http:/www.cdc.gov/nceh/lead/guide/1997/pdf/c2.pdf; www.cdc.gov/ mmwr/PDF/rr/rr5608.pdf

30. Canfield RL, Henderson CR Jr, Cory-Slechta DA et al (2003) Intellectual impairment in children with blood lead concentrations below 10 microg per deciliter. N Engl J Med 348:1517-1526

31. Wilhelm M, Ewers U, Schulz C (2004) Revised and new reference values for some trace elements in blood and urine for human biomonitoring in environmental medicine. Int J Hyg Environ Health 207:6973

32. Wilhelm M, Schulz C, Schwenk M (2006) Revised and new reference values for arsenic, cadmium, lead, and mercury in blood or urine of children: basis for validation of human biomonitoring data in environmental medicine. Int J Hyg Environ Health 209:301-305

33. Barton H (2010) Predicted intake of trace elements and minerals via household drinking water by 6-year-old children from Krakow, Poland. Part 5: zinc. Food Addit Contam A Chem Anal Control Expo Risk Assess 27:315-326

34. Barton $\mathrm{H}$ (2005) Predicted intake of trace elements and minerals via household drinking water by 6-year-old children from Kraków, Poland. Part 2: cadmium, 1997-2001. Food Addit Contam $22: 816-828$

35. CDC 1997. Capillary blood sampling protocol. Available: www.cdc.gov/nceh/lead/publications/1997/ pdf/c2.pdf 
36. Ryabukhin YS (1978) Activation analysis of hair as an indicator of contamination of man by environmental trace element pollutants. Vienna: International Atomic Energy Agency, Report no. IAEA/ RL/50, IAEA, Vienna

37. Linsinger T, Diemer J, Lamberty A et al (2001) Re-certification of the Cd-mass concentration in reconstituted bovine blood BCR-194, -195 and -196. EUR 19765. Luxembourg: Office for Official Publications of the European Communities 2001. BCR information series. ISBN 92-894-0893-6

38. Barton H (2008) Predicted intake of trace elements and minerals via household drinking water by 6-year-old children from Krakow, Poland. Part 3: aluminium. Food Addit Contam A Chem Anal Control Expo Risk Assess 25(5):588-603, PM 18473214

39. International Programme on Chemical Safety. Inorganic lead. Environmental health criteria 165. Geneva: World Health Organization, 1995

40. My H, Kosanovic M, Fahim MA et al (2004) Trace metal profiles in hair samples from children in urban and rural regions of the United Arab Emirates. Vet Hum Toxicol 46:119-121

41. Sanna E, Floris G, Vallascas E (2008) Town and gender effects on hair lead levels in children from three Sardinian towns (Italy) with different environmental backgrounds. Biol Trace Elem Res 124:52-59

42. Razagui IB (2008) A comparative evaluation of three washing procedures for minimizing exogenous trace element contamination in fetal scalp hair of various obstetric outcomes. Biol Trace Elem Res 123:47-57

43. ATSDR 2005. The Agency for Toxic Substances and Disease Registry, Atlanta, Georgia. Toxicological profile for zinc. Available: http://www.atsdr.cdc.gov/ToxProfiles/tp60.pdf

44. Gomes VE, Rosário De Sousa L, Barbosa F Jr et al (2004) In vivo studies on lead content of deciduous teeth superficial enamel of preschool children. Sci Total Environ 320:25-35

45. Haavikko K, Anttila A, Helle A et al (1984) Lead concentrations of enamel and dentine of deciduous teeth of children from two Finnish towns. Arch Environ Health 39(2):78-84

46. Stroh E, Lundh T, Oudin A et al (2009) Geographical patterns in blood lead in relation to industrial emissions and traffic in Swedish children, 1978-2007. BMC Public Health 9:225

47. Kurkjian CR, Flegal AR (2003) Isotopic evidence of the persistent dominance of blood lead concentrations by previous gasoline lead emissions in Yerevan, Armenia. Environ Res 93 (3):308-315

48. Brockhaus A, Collet W, Dolgner R et al (1988) Exposure to lead and cadmium of children living in different areas of north-west Germany: results of biological monitoring studies 1982-1986. Int Arch Occup Environ Health 60:211-222

49. Haavikko K, Anttila A, Helle A et al (1985) Atherosclerosis precursors in Finnish children and adolescents. XIV. Zinc and copper concentrations in deciduous teeth. Acta Paediatr Scand Suppl 318:213-219

50. Scharer K, Veits G, Brockhaus A et al (1991) High lead content of deciduous teeth in chronic renal failure. Pediatr Nephrol 5:704-707

51. Nagaraj G, Sukumar A, Nandlal B et al (2009) Tooth element levels indicating exposure profiles in diabetic and hypertensive subjects from Mysore, India. Biol Trace Elem Res 131:255-262

52. Alatise OI, Schrauzer GN (2010) Lead exposure: a contributing cause of the current breast cancer epidemic in Nigerian women. Biol Trace Elem Res 136(2):127-139. doi:10.1007/s12011-010-8608-2

53. Karakaya A, Ilko M, Ulusu T et al (1996) Lead levels in deciduous teeth of children from urban and suburban regions in Ankara (Turkey). Bull Environ Contam Toxicol 56(1):16-20

54. Karahalil B, Aykanat B, Ertaș N (2007) Dental lead levels in children from two different urban and suburban areas of Turkey. Int J Hyg Environ Health 210:107-112

55. Arruda-Neto JD, De Oliveira MC, Sarkis JE et al (2009) Study of environmental burden of lead in children using teeth as bioindicator. Environ Int 35:614-618

56. Fischer A, Wiechuła D, Postek-Stefańska L et al (2009) Concentrations of metals in maxilla and mandible deciduous and permanent human teeth. Biol Trace Elem Res 132:19-26

57. Barton H, Zachwieja Z, Folta M (2002) Predicted intake of trace elements and minerals via household drinking water by 6-year-old children from Krakow (Poland). Part 1: lead (year 2000). Food Addit Contam 19:906-915

58. Huzior-Bałajewicz A, Pietrzyk JJ, Schlegel-Zawadzka M et al (2001) The influence of lead and cadmium environmental pollution on anthropometric health factors in children. Przegl Lek 58:315-324

59. Alomary A, Al-Momani IF, Massadeh AM (2006) Lead and cadmium in human teeth from Jordan by atomic absorption spectrometry: some factors influencing their concentrations. Sci Total Environ 369:69-75

60. Hernández-Guerrero JC, Jiménez-Farfán MD, Belmont R et al (2004) Lead levels in primary teeth of children living in Mexico City. Int J Paediatr Dent 14:175-181 
61. Chiaradia M, Gulson BL, MacDonald K (1997) Contamination of houses by workers occupationally exposed in a lead-zinc-copper mine and impact on blood lead concentrations in the families. Occup Environ Med 54:117-124

62. Hong SR, Lee SM, Lim NR et al (2009) Association between hair mineral and age, BMI and nutrient intakes among Korean female adults. Nutr Res Pract 3:212-219

63. CDC (2007) Interpreting and managing blood lead levels $<10 \mathrm{microg} / \mathrm{dL}$ in children and reducing childhood exposures to lead: recommendations of CDC's Advisory Committee on Childhood Lead Poisoning Prevention. MMWR Recomm Rep 56 (RR-8):1-16

64. Wilhelm M, Ohnesorge FK, Hötzel D (1990) Cadmium, copper, lead, and zinc concentrations in human scalp and pubic hair. Sci Total Environ 92:199-206

65. CDC (2004) Work Group of the Advisory Committee on Childhood Lead Poisoning Prevention. A review of the evidence of health effects of blood lead levels $<10 \mu \mathrm{g} / \mathrm{dl}$ in children. Centers for Disease Control and Prevention, Atlanta, GA. Available http:/www.cdc.gov/nceh/lead/ACCLPP/meeting Minutes/lessThan10MtgMAR04.pdf

66. Jamieson JA, Taylor CG, Weiler HA (2006) Marginal zinc deficiency exacerbates bone lead accumulation and high dietary zinc attenuates lead accumulation at the expense of bone density in growing rats. Toxicol Sci 92:286-294

67. Kedzierska E (2003) [Concentrations of selected bioelements and toxic metals and their influence on health status of children and youth residing in Szczecin] [Article in Polish]. Ann Acad Med Stetin 49:131-143

68. Benes B, Sladká J, Spevácková V et al (2003) Determination of normal concentration levels of Cd, Cr, $\mathrm{Cu}, \mathrm{Hg}, \mathrm{Pb}$, Se and $\mathrm{Zn}$ in hair of the child population in the Czech Republic. Cent Eur J Public Health $11: 184-186$

69. Tvinnereim HM, Eide R, Riise T (2000) Heavy metals in human primary teeth: some factors influencing the metal concentrations. Sci Total Environ 255:21-27 